2. Sailer AM, van Kuijk SM, Nelemans PJ, Chin AS, Kino A, Huininga M, et al. Computed tomography imaging features in acute uncomplicated Stanford type-
B aortic dissection predict late adverse events. Circ Cardiovasc Imaging. 2017; 10:e005709.
See Article page 1184

\section{Commentary: Type B aortic dissections: Bigger is never better}

\author{
Robert B. Hawkins, MD, MSc, and \\ J. Hunter Mehaffey, MD, MSc
}

Higashigaito and colleagues ${ }^{1}$ report their work examining risk factors for adverse events after type B aortic dissection. They have developed a database of acute uncomplicated type B dissection from their institution and published previously on this cohort and risk factors leading to late complications. $^{2}$ In this analysis, the authors investigated the associations of 8 different aortic morphologic features extracted from long-term follow-up computed tomography scans. These included number and size of intimal tears, intercostal arteries, flap mobility and extent, aortic size, false lumen size and drainage, and extent of thrombus.

This work excludes previously included patients with intramural hematoma, which provides a more homogenous population with increased internal validity. However, they are left with only 47 patients, requiring the use of a composite endpoint of late adverse events (LAEs). Consistent with previous literature, 21 patients $(45 \%)$ developed LAEs over the median 6.6 years of follow-up. This is where the main limitation of the manuscript is found, namely that LAEs were defined as aneurysmal degeneration, rapid growth, new dissection, rupture, malperfusion, or death. The vast majority of events $(86 \%)$ were aneurysmal degeneration. It is therefore relatively unsurprising that the variables associated with increasing lumen size (increased partial false lumen thrombus, increased aortic diameter and increased extent of false lumen) were most associated with LAEs. Although not perfectly applicable in the elastic vasculature of the human body, the law of Laplace states that cylindrical wall tension is proportional to the radius and pressure. Reduced to its most simple form, the question of who will develop LAEs

From the Division of Thoracic and Cardiovascular Surgery, University of Virginia, Charlottesville, Va.

Disclosures: Authors have nothing to disclose with regard to commercial support.

Received for publication Oct 22, 2019; revisions received Oct 22, 2019; accepted for publication Oct 22, 2019; available ahead of print Nov 9, 2019.

Address for reprints: Robert B. Hawkins, MD, MSc, Department of Thoracic and Cardiovascular Surgery, University of Virginia, P.O. Box 800679, Charlottesville, VA 22908 (E-mail: rbh6x@virginia.edu).

J Thorac Cardiovasc Surg 2021;161:1192

$0022-5223 / \$ 36.00$

Copyright (c) 2019 by The American Association for Thoracic Surgery

https://doi.org/10.1016/j.jtcvs.2019.10.117
Check for updates

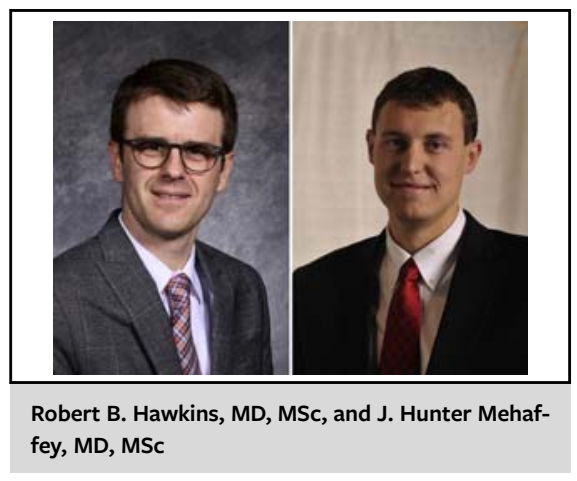

CENTRAL MESSAGE

Increasing overall or false lumen size on

follow-up CT predicts late adverse events

(LAES). However, as LAEs are mostly aneu-

rysmal degeneration, the utility for early

prognostication is limited.

is simply physics. Using a late surrogate such as size on followup seems at best a late signal that the patient is heading toward aneurysmal degeneration requiring repair. Future research needs to focus on early predictors of the fluid dynamics leading to pressurization and future dilation of the aorta. Recent work in this Journal has highlighted possible 4-dimensional technologies that could detect patients at risk for enlargement immediately after dissection. ${ }^{3}$ It is the upfront identification of patients who will need future intervention that could prevent the cost, radiation, and anxiety associated with continuous follow-up after uncomplicated acute type B dissections.

\section{References}

1. Higashigaito K, Sailer AM, van Kuijk SMJ, Willemink MJ, Hahn LD, Hastie TJ, et al. Aortic growth and development of partial false lumen thrombosis are associated with late adverse events in type B aortic dissection. J Thorac Cardiovasc Surg. 2021;161:1184-90.e2.

2. Sailer AM, van Kuijk SM, Nelemans PJ, Chin AS, Kino A, Huininga M, et al. Computed tomography imaging features in acute uncomplicated Stanford typeB aortic dissection predict late adverse events. Circ Cardiovasc Imaging. 2017;10.

3. Burris NS, Patel HJ, Hope MD. Retrograde flow in the false lumen: marker of a false lumen under stress? J Thorac Cardiovasc Surg. 2019;157:488-91. 